\title{
METODE PRAKTIKUM DENGAN MEDIA ANIMASI POWERPOINT : PENGARUH TERHADAP MOTIVASI BELAJAR PESERTA DIDIK SMA NEGERI 1 BELITANG
}

\author{
Qurotul Aini ${ }^{1 *}$, Siti Anisatur Rofiqah ${ }^{2}$, Effendi $^{3}$ \\ 1,2,3 Program Studi Pendidikan Fisika STKIP Nurul Huda Sukaraja, Sumatera Selatan \\ *Coressponding author: ainiqurotu1439@gmail.com
}

Article History:

Received: februari 21, 2021

Revised: maret 12, 2021

Accepted: mei 13, 2021

Published: juni 24, 2021

Keywords: Animasi powerpoint, metode praktikum, motivasi belajar

\begin{abstract}
The purpose of this study was to determine the effect of the application of the practicum method with PowerPoint animation media on the learning motivation of class XI science students at SMA Negeri 1 Belitang in the 2020/2021 academic year. The research design used a posttest-only control design. The population in this study were all students of class XI IPA SMA Negeri 1 Belitang totaling 216 students, and the research sample was 36 students of class XI IPA 2 as the experimental class and 36 students of class XI IPA 1 as the control class. The data collection technique in this study used a questionnaire and then analyzed using the t-test. Based on the results of the analysis, it is known that the level of learning motivation of experimental class students reaches $67 \%$ in the medium category and the level of learning motivation of control class students reaches $64 \%$ in the medium category. After the t-test was carried out, the results of tcount were 3.81 while ttable was 1.99. Because tcount was not between -ttable and +ttable i.e. -1.99 , and +1.99 then, $\mathrm{HO}$ is rejected and $\mathrm{Ha}$ is accepted. Hence, there is a significant influence on the application of the practicum method with PowerPoint animation media on the learning motivation of the students of class XI science at SMA Negeri 1 Belitang in the 2020/2021 academic year.
\end{abstract}

\footnotetext{
Abstrak: Tujuan penelitian ini untuk mengetahui pengaruh signifikan penerapan metode praktikum dengan media animasi powerpoint terhadap motivasi belajar peserta didik kelas XI IPA SMA Negeri 1 Belitang Tahun Pembelajaran 2020/2021. Desain penelitian menggunakan posttest only control desaign. Populasi dalam penelitian ini yaitu seluruh peserta didik kelas XI IPA SMA Negeri 1 Belitang berjumlah 216 peserta didik, sedangkan sampel penelitian kelas XI IPA 2 sebagai kelas eksperimen berjumlah 36 peserta didik dan kelas XI IPA 1 sebagai kelas kontrol berjumlah 36 peserta didik. Pengumpulan data dalam penelitian ini menggunakan angket. Analisis data menggunakan uji $t$. Berdasarkan hasil analisis didapatkan tingkat motivasi belajar peserta didik kelas eksperimen $67 \%$ dengan kategori sedang dan tingkat motivasi belajar peserta didik kelas kontrol 64\% dengan kategori sedang. Terdapat pengaruh yang signifikan penerapan metode praktikum dengan media animasi powerpoint terhadap motivasi belajar peserta didik kelas XI IPA SMA Negeri 1 Belitang Tahun Pembelajaran 2020/2021, dengan $t_{\text {hitung }} 3,81$ sedangkan $t_{\text {tabel }} 1,99$. Karena $t_{\text {hitung }} 3,81$ tidak terletak diantara $-t_{\text {hitung }}$ $<+\mathrm{t}_{\text {hitung }}$ yaitu $-1,99$ dan $+1,99$ maka $\mathrm{H}_{0}$ ditolak dan $\mathrm{H}_{\mathrm{a}}$ diterima.
} 


\section{PENDAHULUAN}

Beberapa aspek dalam pembelajaran diantaranya interaksi peserta didik dan pendidik, peserta didik, pendidik, sumber belajar dan lingkungan belajar serta metode dan media pembelajaran yang berkaitan dengan materi pembelajaran (Hayati, 2017). Pada penerapannya media pembelajaran membutuhkan metode salah satunya metode praktikum (Widayanti et al., 2018; Widayanti \& Yuberti, 2018).

Metode praktikum bertujuan membekali peserta didik agar lebih dapat memahami teori dan praktik (Nisa, 2017). Selain itu juga perlu diterapkan animasi powerpoint yang bertujuan menampilkan program multimedia yang menarik, mudah dalam pembuatan, mudah dalam penggunaan, dan relatif murah (Saputro, 2018). Sehingga motivasi belajar peserta didik dapat dirangsang melalui metode dan media pembelajaran (Baidi, 2019; Putra \& Wardika, 2021; Rita, 2019). Namun, realitanya motivasi peserta didik dalam belajar sangat rendah (Afriana et al., 2017; Aulina, 2018; Lusidawaty et al., 2020; Sulfemi, 2020). Hal ini senada dengan hasil observasi peneliti.

Berdasarkan observasi yang dilakukan peneliti di kelas XI IPA SMA Negeri 1 Belitang Tahun Pembelajaran 2020/2021 semester Ganjil didapatkan data bahwa motivasi belajar peserta didik masih rendah dilihat dari aktivitas belajar yang tinggi dikelas 36,11\%; tekun dalam mengerjakan tugas 30,56\%; ulet dalam mengahadapi kesulitan 33,33\%; adanya informasi dari guru 38,89\%; adanya umpan balik $36,11 \%$ dan adanya penguatan $33.33 \%$. Hal ini disebabkan metode belajar yang masih konvensional dan metode belajar yang masih belum memicu peningkatan motivasi belajar (Aini, 2020; Martanti et al., 2021; Putra \& Wardika, 2021; Solihat et al., 2020).

Penelitian sebelumnya telah menerapkan metode praktikum dalam meningkatkan motivasi belajar (Muzzakir, 2015), selain itu motivasi belajar peserta didik sekolah dasar juga telah ditingkatkan dengan menerapkan Ms Powerpoint (Movitaria \& Y.S, 2019). Fokus pada penelitian ini menerapkan Ms Powerpoint dalam meningkatkan motivasi belajar peserta didik sekolah menengah atas.

\section{METODE}

Penelitian ini menggunakan metode kuasi eksperimen. Desain penelitian menggunakan posttest only control desaign. Populasi dalam penelitian ini yaitu seluruh peserta didik kelas XI IPA SMA Negeri 1 Belitang berjumlah 216 peserta didik, sedangkan sampel penelitian kelas XI IPA 2 sebagai kelas eksperimen berjumlah 36 peserta didik dan kelas XI IPA 1 sebagai kelas kontrol berjumlah 36 peserta didik. Desain penelitian ditunjukkan pada gambar 1 .

\begin{tabular}{|lll|}
\hline $\mathrm{X}_{1}$ & $\mathrm{R}$ & $\mathrm{X}_{2}$ \\
$\mathrm{O}_{2}$ & & $\mathrm{O}_{4}$ \\
\hline
\end{tabular}

Gambar 1. Desain Peneliti

Keterangan:

$\mathrm{R}=$ Kelas yang dipilih secara random

$\mathrm{X}_{1}=$ Perlakuan kelas eksperimen dengan menggunakan metode praktikum dan media animasi powerpoint

$\mathrm{X}_{2}=$ Perlakuan kelas kontrol dengan menggunakan metode konvensional

$\mathrm{O}_{2}=$ Hasil posttest kelas eksperimen

$\mathrm{O}_{4}=$ Hasil posttest kelas kontrol

Instrumen yang digunakan yaitu angket motivasi belajar. Dianalisis menggunakan beberapa syarat 
dilakukannya $u j i-t$.

\section{HASIL DAN PEMBAHASAN}

Temuan hasil penelitian penerapan metode praktikum dengan animasi powerpoint untuk kelas kontrol dan eksperimen dilakukan dengan uji-t, sebelumnya telah dilakukan uji normalitas dan uji homogenitas data yang digunakan. Data bersifat normal dan homogen sehingga dilakukan uji-t.

Adapun hasil uji-t ditunjukkan pada tabel 1.

Tabel 1. Hasil Uji-t

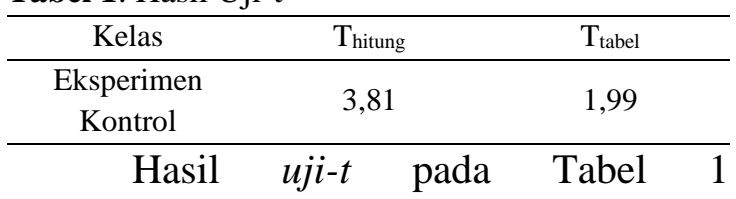

menunjukkan adanya pengaruh yang signifikan penerapan metode praktikum dengan media animasi powerpoint terhadap motivasi belajar peserta didik kelas XI IPA SMA Negeri 1 Belitang Tahun
Pembelajaran 2020/2021. Uraian motivasi belajar yang diperoleh pada penelitian ini ditunjukkan gambar 2 .

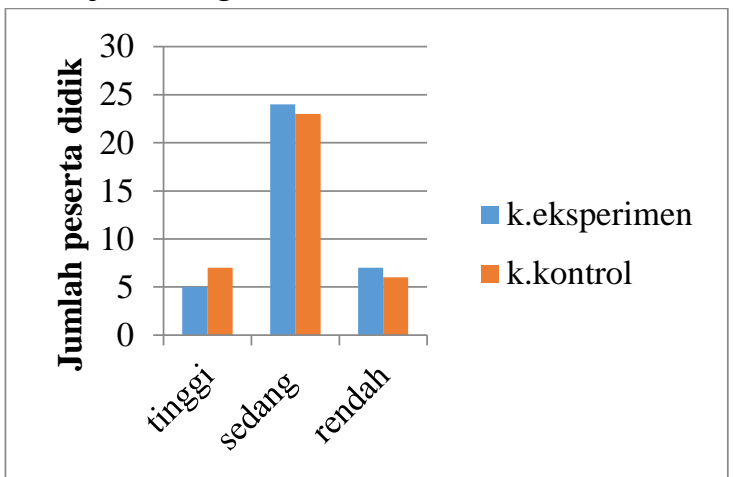

Gambar 2. Hasil Motivasi Belajar Kelas Eksperimen dan Kelas Kontrol

Berdasarkan uraian pada gambar 2 menunjukkan bahwa hasil motivasi belajar menggunakan metode praktikum dan animasi powerpoint lebih tinggi dibanding menggunakan metode konvensional meskipun keduanya masih dalam kategori sedang. Adapun langkah-langkah yang dilakukan dalam penelitian ini ditunjukkan tabel 2.

Tabel 2. Langkah-langkah kelas kontrol dan kelas eksperimen

\begin{tabular}{|c|c|c|}
\hline Fase & Kelas Kontrol & Kelas Eksperimen \\
\hline Pembukaan & $\begin{array}{l}\text { 1. Orientasi } \\
\text { a. Salam } \\
\text { b. Berdo'a } \\
\text { c. Absensi } \\
\text { 2. Apersepsi }\end{array}$ & $\begin{array}{l}\text { 1. Orientasi } \\
\text { a. Salam } \\
\text { b. Berdo'a } \\
\text { c. Absensi } \\
\text { 2. Apersepsi } \\
\text { 3. Motivasi } \\
\text { 4. Pemberian acuan }\end{array}$ \\
\hline $\begin{array}{l}\text { Kegiatan } \\
\text { Inti }\end{array}$ & $\begin{array}{l}\text { 1. Penyajian } \\
\text { bahan ajar } \\
\text { kesetimbangan } \\
\text { benda tegar } \\
\text { 2. Kesimpulan }\end{array}$ & $\begin{array}{l}\text { 1. Pemberian masalah mengenai kesetimbangan benda tegar } \\
\text { 2. Identifikasi masalah mengenai kesetimbangan benda tegar } \\
\text { 3. Pengumpulan data melalui praktikum mengenai kesetimbangan benda tegar } \\
\text { 4. Pengolahan data dari hasil praktikum mengenai kesetimbangan benda tegar } \\
\text { 5. Pembuktian hasil praktikum dengan teori yang telah dipelajari mengenai } \\
\text { kesetimbangan benda tegar } \\
\text { 6. Penarikan kesimpulan mengenai materi pembelajaran kesetimbangan benda tegar }\end{array}$ \\
\hline Penutup & 1. Evaluasi & $\begin{array}{l}\text { 1. Penarikan kesimpulan } \\
\text { 2. Evaluasi }\end{array}$ \\
\hline
\end{tabular}

Materi pembelajaran yang diterapkan dalam penelitian ini yaitu materi pembelajaran kesetimbangan benda tegar. Berdasarkan Tabel 2, pembelajaran di kelas kontrol menerapkan metode konvensional.
Metode ini meliputi 3 fase yaitu pembukaan yang meliputi orientasi dan apersepsi; kegiatan inti yang meliputi penyajian materi, pembahasan materi dan kesimpulan; serta penutup yang meliputi 
kegiatan evaluasi. Kegiatan pembukaan dimulai dengan orientasi, pendidik memberi salam dan dijawab oleh peserta didik, dilanjutkan berdo'a yang dipimpin oleh ketua kelas, kemudian pendidik memeriksa keadaan dan absensi kelas serta dilanjutkan dengan memberikan apersepsi berupa pertanyaan yang berkenaan dengan materi yang telah dipelajari sebelumnya.

Fase kedua kegiatan inti, pendidik menyajikan materi pembelajaran kesetimbangan benda tegar dengan ceramah dan didengarkan oleh peserta didik. Tahap inti selanjutnya yaitu kesimpulan, pendidik memberikan tugas kepada peserta didik untuk membuat kesimpulan mengenai materi pembelajaran kesetimbangan benda tegar. Fase ketiga yaitu evaluasi, pendidik melakukan evaluasi kepada peserta didik untuk mengetahui pemahamnya mengenai materi yang telah dibahas.

Kelas eksperimen pada penelitian ini menerapkan metode praktikum yang diintegrasikan dengan animasi powerpoint. Metode pada pembelajaran ini meliputi pembukaan, kegiatan ini dan penutup. Fase pembukaan meliputi orientasi, apersepsi, motivasi dan pemberian acuan; fase kegiatan inti meliputi pemberian masalah, identifikasi masalah, pengumpulan data, pembuktian dan penarikan kesimpulan; fase penutup meliputi kesimpulan dan evaluasi.

Fase pembukaan dimulai dari orientasi yaitu salam yang diucapkan pendidik, berdoa yang dipimpin ketua kelas dan pengecekkan absensi kelas ataupun keadaan peserta didik. Selanjutnya yaitu apersepsi, pendidik menanyakan pembahasan sebelumnya ditambah dengan memberikan motivasi sebagai pembangkit semangat serta penyampaian tujuan pembelajaran dan manfaat mengenai materi pembelajaran yang akan dibahas.

Fase kedua yaitu kegiatan inti, pendidik memberikan masalah sesuai dengan materi pembelajaran, dari masalah inilah peserta didik dituntut untuk mengidentifikasi masalah tersebut dari berbagai sumber. Tahap ini dilanjutkan dengan melakukan praktikum sesuai acuan dalam media animasi powerpoint dan Lembar Kerja Peserta Didik (LKPD), setelah data praktikum didapatkan dan diolah sesuai instruksi peserta didik membuktikan kebenaran dari praktikum tersebut sesuai teori yang didapatkan sebelumnya. Hasil data dari praktikum tersebut didaptkan secara praktik dan teori dan ditarik kesimpulan dari hasil data tersebut.

Fase ketiga yaitu penutup, pendidik dan peserta didik bersama-sama meyimpulkan keseluruhan pembelajaran, serta untuk mengetahui pemahaman peserta didik mengenai kesetimbangan benda tegar. Penelitian dengan metode ini bisa diterapkan pada masa pandemi Covid-19 ataupun tatap muka di kelas, sehingga motivasi belajar peserta didik bisa meningkat. Namun, motivasi belajar kelas kontrol dan kelas eksperimen masih dalam tingkatan sedang meskipun motivasi belajar kelas eksperimen lebih tinggi. Hal ini dikarenakan penelitian dilakukan secara online dan pendidik belum terlalu bisa untuk mengontrol keadaan peserta didik.

Meskipun demikian, penelitian ini sejalan dengan mpeneliti sebelumnya bahwa dengan menggunakan praktikum peserta didik dapat meningkatkan motivasinya (Aini, 2020; Muzzakir, 2015). Temuan lain dari penelitian ini, meskipun pada keadaan pandemi covid berlangsung metode praktikum juga dapat diterapkan meskipun belum secara maksimal peserta didik terbiasa menggunakan praktikum 
secara online.

\section{SIMPULAN DAN SARAN}

Motivasi belajar peserta didik yang pembelajarannya menerapkan metode praktikum dengan animasi powerpoint lebih tinggi dibandingkan dengan motivasi belajar peserta didik yang pembelajarannya menerapkan metode konvensional pada materi pembelajaran Kesetimbangan Benda Tegar. Penelitian selanjutnya, diharapkan lebih mengembangkan media pembelajaran animasi powerpoint yang diintegrasikan dengan metode atau aplikasi lain yang lebih kreatif.

\section{DAFTAR PUSTAKA}

Afriana, J., Permanasari, A., \& Fitriani, A. (2017). Penerapan project based learning terintegrasi STEM untuk meningkatkan literasi sains siswa ditinjau dari gender. Jurnal Inovasi Pendidikan IPA, 2(2), 202. https://doi.org/10.21831/jipi.v2i2.856 1

Aini. (2020). Pengaruh Metode Praktikum dengan Media Animasi Powerpoint Terhadap Motivasi Belajar Peserta Didik SMA Negeri 1 Belitang Tahun Pembelajaran 2020/2021.

Aulina, C. N. (2018). Penerapan Metode Whole Brain Teaching dalam Meningkatkan Motivasi Belajar Anak Usia Dini. Jurnal Obsesi: Jurnal Pendidikan Anak Usia Dini, 2(1), 1. https://doi.org/10.31004/obsesi.v2i1.1

Baidi. (2019). The Role of Parents' Interests and Attitudes in Motivating Them to Homeschool Their Children. Journal of Social Studies Education Research, 10(1), 156-177.

Hayati. (2017). Belajar dan Pembelajaran Berbasis Learning. Graha Cendikia.

Lusidawaty, V., Fitria, Y., MMiaz, Y., \& Zikri, A. (2020). Pembelajaran IPA dengan Strategi Pembelajaran Inkuiri untuk Meningkatkan Keterampilan Proses Sains dan Motivasi Belajar
Siswa Di Sekolah Dasar. Jurnal Basicedu, 4(1), 168-174.

Martanti, N., Malika, E. R., \& Setyaningsih, A. (2021). Pengaruh Metode Pembelajaran Eksperimen Virtual Menggunakan PhET Terhadap Hasil Belajar Kognitif Siswa. KONSTELASI: Konvergensi Teknologi Dan Sistem Informasi Pengaruh, 5(1), 83-92.

Movitaria, M. ., \& Y.S. (2019). Penggunaan Microsoft Powerpoint Terhadap Motivasi Siswa. Jurnal Seminar Nasional Pendidikan Dasar \& Call For Papers, 1(1), 161-168.

Muzzakir, A. . (2015). Pengaruh Pelaksanaan Praktikum Berbasis Laboratorium Virtual Terhadap Peningkatan Motivasi dan Kreativitas Siswa. Jurnal Pendidikan Sains Indonesia, 3(1), 125-134.

Nisa, U. M. (2017). Metode Praktikum Untuk Meningkatkan Pemahaman dan Hasil Belajar Siswa Kelas V MI YPPI 1945 Babat pada Materi Zat Tunggal dan Campuran. Journal Proceeding Biology Education Conference, 14(1), 62-68.

Putra, I. P. S. A., \& Wardika, I. W. G. (2021). Penggunaan Aplikasi Google Classroom dalam Upaya Meningkatkan Motivasi Belajar Matematika Mahasiswa. Jurnal Emasains: Jurnal Edukasi Matematika Dan Sains, 10(1), 111120.

Rita. (2019). The Effect of Learning Methods and Learning Motivation On Indonesian Learning Outcomes Class X Students of Panca Budi Medan High School. BirLE- Journal, 2(1), 132137.

Saputro, N. (2018). Pengaruh Penggunaan Media Powerpoint terhadap Hasil Belajar Tematik Siswa Kelas IV di SDN 1 Surabaya Bandar Lampung. Jurnal Pendidikan Dasar, 7(5).

Solihat, A., Hendracipta, N., \& Yuliana, R. (2020). Pengembangan Media Puppet Book Berbasis Pembelajaran 
Multiliterasi pada Peserta Didik Sekolah Dasar. Jurnal Bidang Pendidikan Dasar, 4(2), 134-144.

Sulfemi, W. B. (2020). Hubungan Sarana Prasarana Sekolah Dengan Motivasi Mengajar Guru Di SMA Negeri Pamijahan Kabupaten Bogor. Jurnal Ilmiah Edutecno, 22(1), 1-19. https://doi.org/10.35542/osf.io/p2fae

Widayanti, \& Yuberti. (2018). Pengembangan Alat Praktikum Sederhana Sebagai Media Praktikum Mahasiswa. JIPFRI (Jurnal Inovasi Pendidikan Fisika Dan Riset Ilmiah), 2(1), 21-27. https://doi.org/10.30599/jipfri.v2i1.16 1

Widayanti, Yuberti, Irwandani, \& Hamid, A. (2018). Pengembangan Lembar Kerja Praktikum Percobaan Melde Berbasis Project Based Learning. Jurnal Pendidikan Sains Indonesia, 06(01), 24-31. https://doi.org/10.24815/jpsi.v6i1.109 08 